\title{
Chronic Inflammation and Low-Dose Glucocorticoid Effects on Glucose Metabolism in Premenopausal Females With Rheumatoid Arthritis Free of Conventional Metabolic Risk Factors
}

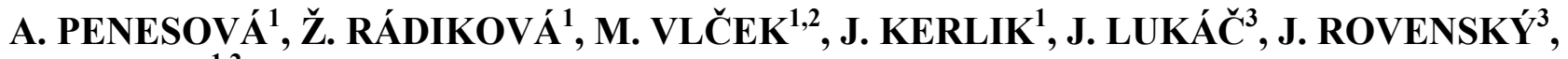 \\ R. IMRICH ${ }^{1,2}$
}

${ }^{1}$ Laboratory of Human Endocrinology, Institute of Experimental Endocrinology, Slovak Academy of Sciences, Bratislava, Slovakia, ${ }^{2}$ Center for Molecular Medicine, Slovak Academy of Sciences, Bratislava, Slovakia, ${ }^{3}$ National Institute of Rheumatic Diseases, Piestany, Slovakia

Received March 19, 2012

Accepted August 23, 2012

On-line November 22, 2012

\begin{abstract}
Summary
Chronic systemic inflammation is associated with increased cardiovascular mortality in patients with rheumatoid arthritis (RA). The aim of our study was to investigate association of glucose metabolism and inflammatory markers in a group of patients with rheumatoid arthritis free of other metabolic risk factors. Twenty-two premenopausal RA females (11 patients on low-dose GC (<8.5 mg/day of prednisone or equivalent), 11 patients without glucocorticoid therapy) and 15 age- and BMImatched healthy females underwent the oral glucose tolerance test. The insulin sensitivity indices according Matsuda (ISI MAT $_{\text {) }}$

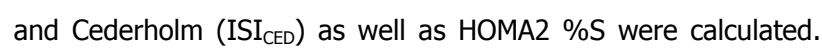
Cytokines, lipid profile, non-esterified fatty acids (NEFA) and plasminogen activator inhibitor-1 (PAI-1) were measured in baseline blood samples. Despite elevated interleukin IL- 6 and TNF alpha, glucose, insulin and C-peptide responses to oral glucose load as well as ISI $_{\text {MAT, }}$ ISI $_{\text {CED, }}$ PAI-1 and NEFA were comparable in both RA groups and healthy controls. HOMA $2 \% \mathrm{~S}$ correlated with disease activity. In conclusions, low-dose glucocorticoid treatment does not lead to glucose metabolism impairment in RA patients without other metabolic risk factors. Increased cardiovascular mortality and morbidity is probably due to a direct effect of systemic inflammation on myocardium and/or blood vessels.
\end{abstract}

\section{Key words}

Inflammation - Glucose metabolism - Rheumatoid arthritis • Insulin sensitivity • Glucocorticoid treatment

\section{Corresponding author}

Adela Penesova, Laboratory of Human Endocrinology, Institute of Experimental Endocrinology, Slovak Academy of Sciences, Vlarska 3-7, 83106 Bratislava, Slovak Republic. Fax: +421 254 7749 42. E-mail: adela.penesova@savba.sk

\section{Introduction}

Cardiovascular mortality in patients with rheumatoid arthritis (RA) is approximately double compared to the general population (Sattar et al. 2003a.b, Gonzalez et al. 2007, Meune et al. 2010). An incidence of cardiovascular events in RA cannot be fully explained by traditional cardiac risk factors (del Rincon et al. 2001). Most of the cardiovascular risk in RA has been attributed to accelerated atherosclerosis; however the mechanisms causing impaired cardiovascular function have not been completely clarified yet.

Inflammation plays a major role in all stages of atherogenesis ranging from fatty streak formation, plaque destabilization to plaque rupture (Rocha and Libby 2009). It has been hypothesized that systemic inflammation affects blood vessels leads to vasculitis (Sattar et al. 2003a,b), endothelial dysfunction resulting in atherosclerosis acceleration (Wang and Feng 2004). Higher C-reactive protein (CRP), hyperinsulinemia, and hypertriglyceridemia as a part of metabolic syndrome are well known risk factors of atherosclerosis (Sattar et al. 2003a,b). Higher frequency of metabolic syndrome 
features was found in RA patients (Svenson et al. 1988, Dessein et al. 2006, La Montagna et al. 2007, Naranjo et al. 2008). Moreover, increased levels of proinflammatory cytokines in RA seem to be independent of the traditional cardiovascular risk factors (MaraditKremers et al. 2005).

The data accumulated so far suggest increased circulating levels of cytokines in RA can independently contribute to accelerated atherosclerosis through impaired insulin sensitivity with subsequent hyperinsulinemia and changes in lipid metabolism (Pamuk et al. 2006, Libby 2008, McKellar et al. 2009, Pemberton et al. 2009). The majority of studies estimated insulin sensitivity based on a fasting plasma glucose and insulin concentrations (Dessein et al. 2006, Chung et al. 2008). However, decreased peripheral tissue insulin sensitivity may be compensated for a long time by postprandial hyperinsulinemia without any changes in fasting glucose and insulin. Only a few studies reported insulin resistance in RA patients using the oral or intravenous glucose tolerance tests or euglycemic hyperinsulinemic clamp (Paolisso et al. 1991, Rosenvinge et al. 2007). Furthermore, other metabolic risk factors such as higher age, obesity, hypertension, dyslipidemia, or endocrine disturbances may overlap with the effect of inflammation on impaired glucose metabolism in RA patients.

Chronic glucocorticoid treatment has been considered to be an independent risk factor of cardiovascular and metabolic diseases (Dessein et al. 2004). Adverse effect of chronic glucocorticoid treatment is dose-related. Recently, growing evidence suggest that low-dose glucocorticoid treatment $(<7.5 \mathrm{mg}$ prednisone or equivalent per day) is relatively safe in RA (Da Silva et al. 2006, Toms et al. 2008). Nevertheless, possible metabolic side effects of glucocorticoids could contribute to cardiovascular risk in RA.

The first aim of our study was to analyze effects of chronic inflammation on glucose metabolism and insulin sensitivity in RA patients free of "traditional" metabolic risk factors. We hypothesized that insulin resistance and/or hyperinsulinemia is present in these patients, and parameters of insulin sensitivity are inversely associated with inflammatory markers. The second aim of our study was to evaluate effect of lowdose glucocorticoid treatment on studied metabolic parameters. We expected the glucocorticoid treatment is associated with glucose and lipid perturbations in RA. The study was performed in non-diabetic subjects without obesity, hypertension, cardiovascular and other comorbidities to avoid possible confounding effects by preexisting metabolic syndrome risk factors.

\section{Materials and Methods}

Twenty-two $(n=22)$ female patients fulfilling the 2010 ACR-EULAR classification criteria for RA were studied. The patients were recruited from the National Institute of Rheumatic Diseases in Piestany, Slovakia. Fifteen ( $\mathrm{n}=15)$ age- and body mass index (BMI) -matched healthy female subjects served as controls. Basic characteristics of all subjects enrolled in the study are summarized in Table 1. All the studied subjects were non-smokers, had negative history of endocrine disorders, diabetes, age limit was 18-40 years, BMI limit was 18-25 $\mathrm{kg} / \mathrm{m}^{2}$. The last dose of the medicaments was administered 24 hours prior to the investigation. Inclusion criteria for GC+ group were low-dose of glucocorticoid (GC) treatment (less than $8.5 \mathrm{mg}$ of prednisone or equivalent per day) and duration of the GC therapy was at least 2 years. RA activity was quantified as disease activity score 28 (DAS28) with three variables i.e. number of swollen joints, number of tender joints and plasma CRP using an online calculator http://www.dasscore.nl/dasculators.html. All subjects gave informed written consent and the study was approved by the Ethics Committee of the National Institute of Rheumatic Diseases, Piestany, Slovakia in agreement with the ethical guidelines of the Declaration of Helsinki as revised in 2000 .

Both patients and controls were asked to fast and restrain from the use of strong physical activity for 12 hours prior to the examination. Upon the arrival in the laboratory at 8:00 AM, cubital vein of one arm was cannulated. Baseline blood sample was taken at least $30 \mathrm{~min}$ after the i.v. catheter insertion to avoid the effect of acute stress of venipuncture.

During the oral glucose tolerance test (oGTT), the subjects were asked to ingest a solution containing $75 \mathrm{~g}$ glucose. Blood samples were collected before (0 min) and 15, 30, 45, 60, 75, 90, 105, and 120 min after glucose ingestion. After centrifugation at $4{ }^{\circ} \mathrm{C}$, all plasma and serum aliquots were stored at $-20^{\circ} \mathrm{C}$ until assayed. Plasma glucose concentrations and fasting serum total cholesterol, high-density lipoprotein (HDL) cholesterol, and triglyceride (TG) levels were measured with enzymatic kits (Roche Diagnostics, Lewes, UK) using an autoanalyzer Hitachi 911 (Roche Diagnostics, Lewes, UK). Serum levels of non-esterified fatty acids (NEFA) at 
baseline and in 30, 60, 90 and 120 min were measured spectrophotometrically by a commercial kit (Randox Laboratories Ltd, Crumlin, Co. Antrim, UK). ELISA kit (Diagnostica Stago, Asnieres, France) was used to measure fasting plasma PAI-1. Insulin and C-peptide levels were measured by IRMA kits (Immunotech S.A.,
Marseille, France). Plasma interleukin 6 (IL-6), and tumor necrosis factor alpha (TNF $\alpha)$ concentrations were assayed using bead-based immunoassay kit (Bio-Plex, Bio-Rad Laboratories, Hercules, CA, USA). C-reactive protein (CRP) concentrations were assayed by immunoturbidimetric assay.

Table 1. Basic clinical and inflammatory parameters in patients with rheumatoid arthritis on low-dose glucocorticoids (RA GC+), rheumatoid arthritis patients not treated with glucocorticoids (RA GC-) and healthy controls.

\begin{tabular}{|c|c|c|c|c|}
\hline & $\begin{array}{c}\text { Controls } \\
(n=15)\end{array}$ & $\begin{array}{l}\text { RA all } \\
(n=22)\end{array}$ & $\begin{array}{c}\text { RA GC+ } \\
(\mathrm{n}=11)\end{array}$ & $\begin{array}{c}\text { RA GC- } \\
(n=11)\end{array}$ \\
\hline Age (yrs) & $29.9 \pm 5.2$ & $30.0 \pm 5.8$ & $30.6 \pm 6.7$ & $29.5 \pm 5.2$ \\
\hline$B M I\left(\mathrm{~kg} / \mathrm{m}^{2}\right)$ & $21.6 \pm 2.0$ & $21.4 \pm 2.7$ & $21.3 \pm 2.4$ & $21.5 \pm 3.1$ \\
\hline Disease duration (yrs) & - & $7.5 \pm 3.4$ & $6.7 \pm 1.7$ & $8.3 \pm 4.5$ \\
\hline$D A S 28$ & - & $3.3 \pm 1.1$ & $3.4 \pm 1.3$ & $3.2 \pm 0.9$ \\
\hline $\begin{array}{l}\text { Dose of prednison or equivalent } \\
(\mathrm{mg} / \text { day })\end{array}$ & - & $4.2 \pm 1.9$ & $4.2 \pm 1.9$ & - \\
\hline NSAIDs (number of patients) & - & 22 & 11 & 11 \\
\hline MTX (number of patients) & - & 19 & 9 & 10 \\
\hline DMARDs (number of patients) & - & 12 & 6 & 6 \\
\hline Total cholesterol $(\mathrm{mmol} / \mathrm{l})$ & $3.67 \pm 0.62$ & $3.49 \pm 0.65$ & $3.35 \pm 0.74$ & $3.62 \pm 0.56$ \\
\hline HDL cholesterol (mmol/l) & $0.96 \pm 0.20$ & $0.92 \pm 0.18$ & $0.90 \pm 0.19$ & $0.95 \pm 0.17$ \\
\hline$T G(\mathrm{mmol} / \mathrm{l})$ & $0.70 \pm 0.19$ & $0.74 \pm 0.25$ & $0.82 \pm 0.19$ & $0.66 \pm 0.29$ \\
\hline NEFA $(\mathrm{mmol} / \mathrm{l})$ & $0.75 \pm 0.25$ & $0.65 \pm 0.25$ & $0.68 \pm 0.26$ & $0.63 \pm 0.25$ \\
\hline$P A I-1(n g / m l)$ & $29.9 \pm 17.2$ & $36.0 \pm 18.3$ & $35.9 \pm 19.2$ & $36.0 \pm 18.3$ \\
\hline$I L-6(p g / m l)$ & $1.4 \pm 1.8$ & $18.7 \pm 28.3^{* * *}$ & $30.6 \pm 36.3^{* *}$ & $6.8 \pm 7.1^{* *}$ \\
\hline TNF alpha $(p g / m l)$ & $0.6 \pm 1.1$ & $13.6 \pm 53.6$ & $26.0 \pm 75.5^{*}$ & $1.1 \pm 2.1$ \\
\hline$C R P(m g / l)$ & $1.2 \pm 3.8$ & $7.4 \pm 14.0^{* *}$ & $11.6 \pm 19.0^{* *}$ & $3.3 \pm 3.5^{*}$ \\
\hline
\end{tabular}

Data are expressed as mean $\pm \mathrm{SD}$. $* \mathrm{p}<0.05, * * \mathrm{p}<0.01, * * * \mathrm{p}<0.001$ vs. Controls. Abbreviations: RA, rheumatoid arthritis; GC, glucocorticoids; BMI, body mass index; BF, body fat; NSAIDs, non-steroid anti-inflammatory drugs; MTX, metothrexate; DMARDs, disease modifying antirheumatic drugs; HDL, high-density lipoprotein; TG, triglycerides; NEFA, non-esterified fatty acids; PAI-1, plasminogen activator inhibitor factor 1; IL-6, interleukin 6; TNF, tumor necrosis factor; CRP, C-reactive protein.

The insulinogenic index was calculated as the ratio of incremental insulin to incremental glucose concentrations $30 \mathrm{~min}$ after glucose ingestion (Mari et al. 2008). From fasting glucose and insulin concentrations index of insulin resistance IR HOMA was calculated (Matthews et al. 1985). Similarly, the updated HOMA2 model was used to estimate the insulin resistance (HOMA2-IR), insulin sensitivity (HOMA2-\%S) and $\beta$ cell function (HOMA2-\%B) from fasting glucose and insulin levels (Wallace et al. 2004). Glucose and insulin concentrations from the oral glucose tolerance tests were used to calculate following indices of insulin sensitivity: index of peripheral insulin sensitivity as proposed by Cederholm and Wibell (ISI $I_{\text {CED }}$ ) (Cederholm and Wibell
1990); and composite whole body insulin sensitivity index as proposed by Matsuda and DeFronzo (ISI $\mathrm{IAT}_{\mathrm{MAT}}$ ) (Matsuda and DeFronzo 1999). During the OGTT, areas under the curves (AUC) of glucose, insulin and C-peptide were calculated by means of the trapezoidal rule.

\section{Statistics}

ANOVA was used to determine differences in basal parameters and cytokine concentrations among RA groups and controls. General Linear Model repeated measures (GLM-RM) procedure was used to determine the differences in glucose, insulin and C-peptide responses during oral glucose tolerance test between RA patients and controls. All calculated indices of insulin 
sensitivity were correlated with the measured cytokines, CRP, DAS28 and PAI-1 with Pearson's correlation. Statistical evaluation was performed using the SPSS 11.5 program (SPSS Inc., Chicago, IL, USA). The results are expressed as the mean $\pm \mathrm{SD}$. Differences were considered significant at $\mathrm{p}<0.05$.
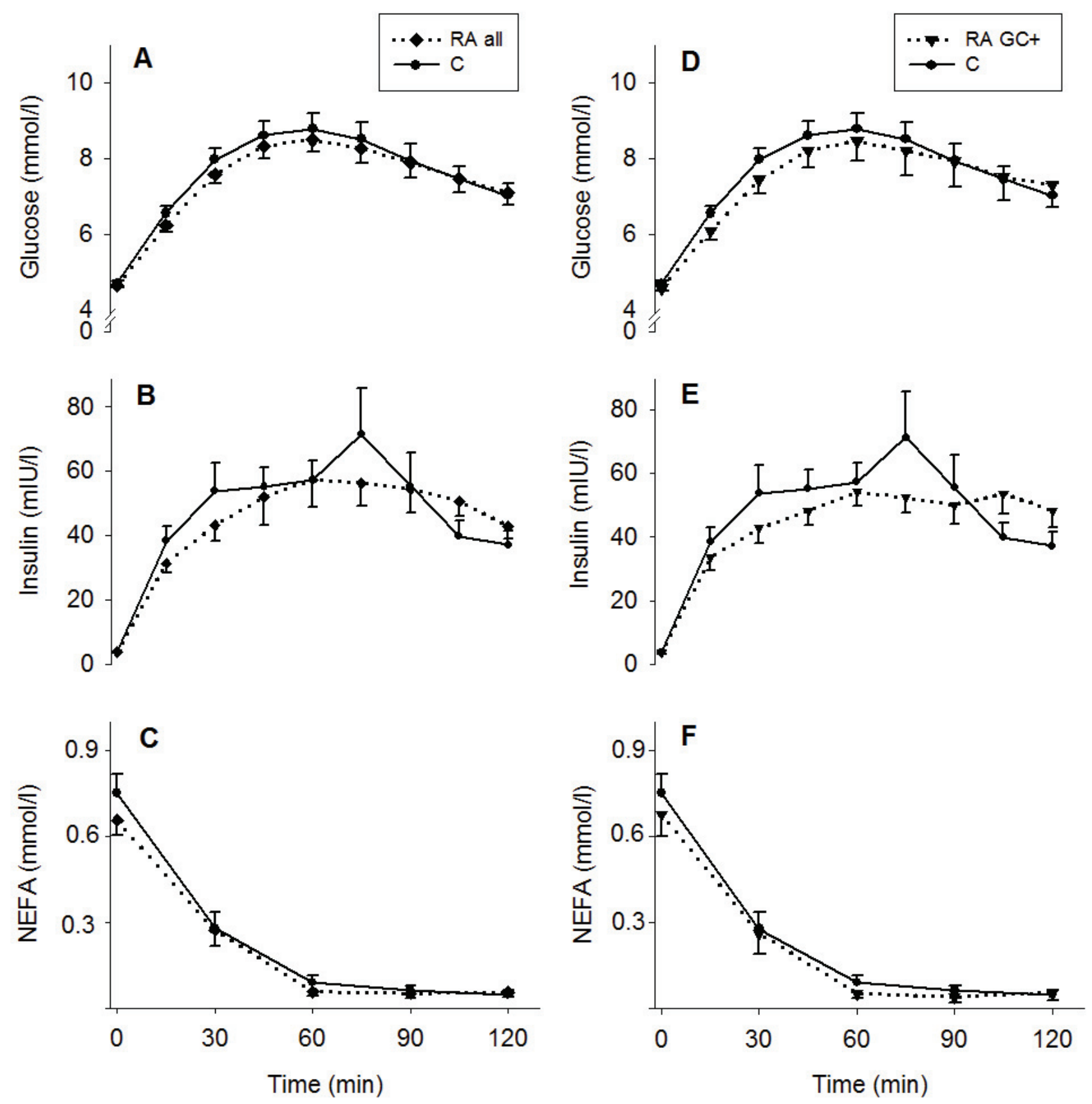

Fig. 1. Plasma glucose (A), insulin (B), and serum NEFA (C) concentrations in all RA patients (diamonds) and controls during oGTT; plasma glucose (D), insulin (E), and serum NEFA (F) concentrations in RA patients with glucocorticoid treatment (RA GC+, open triangles) and controls during oGTT. (Data are expressed as mean $\pm \mathrm{SE}$.)

\section{Results}

There were no significant differences in anthropometric parameters among all three groups. As expected RA patient had higher IL-6 ( $\mathrm{p}=0.001)$, CRP levels $(p=0.003)$, and tendency to higher TNF alpha $(\mathrm{p}=0.057)$ compared to healthy controls. The mean fasting total and HDL cholesterol, triglycerides and baseline PAI-1 were comparable in all groups (Table 1).

Impaired glucose tolerance was found in 4 RA subjects treated with glucocorticoids, 4 subjects in RA patients untreated with glucocorticoids and in 4 control 
subjects. Fasting, as well as 2-hour glucose, insulin, Cpeptide, PAI-1 and serum NEFA concentrations were comparable in RA and controls. During the oral glucose tolerance test glucose, insulin and C-peptide increased significantly $(p<0.001)$ and serum NEFA significantly decreased $(p<0.001)$, however the changes were comparable between two RA patient groups and controls (Fig. 1). There were no significant differences in insulin sensitivity indices among RA groups and controls (Table 2).

Table 2. Insulin sensitivity indices (ISI) in patients with rheumatoid arthritis (RA) on low-dose glucocorticoids (RA GC+), in RA patients not treated with glucocorticoids (RA GC-) and in healthy controls.

\begin{tabular}{|c|c|c|c|c|}
\hline & $\begin{array}{c}\text { Controls } \\
(n=15)\end{array}$ & $\begin{array}{l}\text { RA all } \\
(n=22)\end{array}$ & $\begin{array}{c}\text { RA GC+ } \\
(\mathrm{n}=11)\end{array}$ & $\begin{array}{c}\text { RA GC- } \\
(n=11)\end{array}$ \\
\hline IR HOMA & $0.83 \pm 0.39$ & $0.83 \pm 0.42$ & $0.82 \pm 0.42$ & $0.84 \pm 0.44$ \\
\hline$H O M A 2-I R$ & $0.51 \pm 0.22$ & $0.51 \pm 0.24$ & $0.50 \pm 0.24$ & $0.51 \pm 0.25$ \\
\hline HOMA2-\%B & $67 \pm 16$ & $68 \pm 15$ & $70 \pm 17$ & $66 \pm 15$ \\
\hline HOMA2-\%S & $228 \pm 83$ & $242 \pm 115$ & $236 \pm 68$ & $248 \pm 136$ \\
\hline Insulinogenic index (mU.mmol. $l^{-1}$ ) & $15.5 \pm 9.2$ & $14.5 \pm 7.4$ & $15.5 \pm 7.1$ & $13.5 \pm 7.8$ \\
\hline$A U C_{G L U}(\mathrm{mmol} / \mathrm{l} . \mathrm{min})$ & $926 \pm 129$ & $902 \pm 147$ & $897 \pm 176$ & $907 \pm 120$ \\
\hline$A U C_{I N Z}(\mu U / l . m i n)$ & $5.9 \pm 2.9$ & $5.5 \pm 2.8$ & $5.4 \pm 1.5$ & $5.6 \pm 3.7$ \\
\hline$A U C_{C-P E P}\left(x 10^{3} \mathrm{pmol} / \mathrm{l} . \mathrm{min}\right)$ & $274 \pm 79$ & $275 \pm 71$ & $279 \pm 49$ & $271 \pm 91$ \\
\hline$I S I_{M A T}$ & $8.57 \pm 2.83$ & $9.07 \pm 3.68$ & $8.94 \pm 3.13$ & $9.20 \pm 4.32$ \\
\hline$I S I_{C E D}$ & $50.8 \pm 8.8$ & $53.6 \pm 12.8$ & $53.5 \pm 14.6$ & $53.7 \pm 11.5$ \\
\hline
\end{tabular}

Patients vs. Controls $* \mathrm{p}<0.05$. Abbreviations: RA, rheumatoid arthritis; GC, glucocorticoid; HOMA, homeostasis model assessment; IR, insulin resistance; HOMA2-\%B, homeostasis model assessment to estimate b-cell function; HOMA2-\%S, HOMA indexes of insulin sensitivity; HOMA2-IR, HOMA to estimate insulin resistance; $A U C_{G L U}$, area under the curve of glucose; $A U C_{I N Z}$ area under the curve of insulin; $A \cup C_{C-P E P}$, area under the curve of C-peptide; ISI, insulin sensitivity index.

There were no differences in the above mentioned parameters between RA patients treated with glucocorticoids and glucocorticoid-untreated patients. Similarly, there were no differences in all studied metabolic parameters between RA patients with low (DAS28 $\leq 3.2)$ and moderate to high disease activity (DAS28 $>3.2$ ).

Area under the curve of insulin correlated negatively with baseline IL- 6 concentrations $(r=-0.328$, $\mathrm{p}=0.04)$. HOMA \%B negatively correlated with disease activity score DAS28 $(r=-0.533, p=0.01)$. There were no other significant correlations between the studied inflammatory markers, DAS28, NEFA, PAI-1 and insulin sensitivity indices found (data not shown).

\section{Discussion}

Chronic inflammation has been considered one of the risk factors participating on accelerated atherosclerosis not only in association with RA but also as an independent risk factor of cardiometabolic syndrome in general. To better separate effects of chronic inflammation from other risk factors such as hypertension or obesity, an approach used in our study was to investigate metabolic parameters in patients with chronic inflammatory disease without the "traditional" risk factors. Results of the present study showed the subjects with long-established diagnosis of RA but without other cardiometabolic risk factors had no signs of insulin resistance/sensitivity. Moreover, RA patients in our study had normal antilipolytic effect of insulin as indicated by comparable decline of NEFA during oGTT and normal lipid profile. As expected, RA patients had higher IL-6 and TNF alpha serum concentrations, however we did not observe any significant relationship between metabolic parameters and inflammatory cytokines measured in our study. Decreased insulin sensitivity in RA patients based on oGTT and hyperinsulinemic clamp has been reported previously (Paolisso et al. 1991, Rosenvinge et al. 2007). Svenson and coworkers found that impaired glucose handling is related to insulin resistance in patients with active RA (Svenson et al. 1988). Moreover these patients were treated with high dose of glucocorticoids. Our results about negative association between HOMA $2 \% \mathrm{~B}$ 
and DAS28 is in a good agreement with study of (Dessein and Joffe 2006). They found that DAS28 was a negative predictor of beta cell function in RA patients. On the other hand authors of the latter study (Chung et al. 2008) found that the HOMA index positively correlated with IL-6, CRP levels, erythrocytes sedimentation rate, and DAS28; even after adjusted for age, sex, race, BMI, and current use of corticosteroids.

The prevailing dogma is that IL-6 promotes insulin resistance and thus contributes to obesity development. This assumption is supported by finding of elevated IL-6 in obese patients (Hotamisligil et al. 1993, Yudkin et al. 2000, Fernandez-Real and Ricart 2003, Shoelson et al. 2006). Our results do not support the hypothesis that chronic inflammation in rheumatic diseases is a marker of increased risk for insulin resistance. It has been a matter of discussion whether or not IL-6 should be considered a "bad guy " or a "good guy" with regard to its metabolic actions (Febbraio et al. 2010). Studies demonstrating that IL-6 is released from skeletal muscle have shed a different light on the role of IL-6 in the etiology of insulin resistance since insulin action is known to be enhanced in period immediately after exercise (Pedersen and Febbraio 2005). Stouthard et al. (1995) demonstrated that infusion of rhIL-6 increased whole body basal and insulin stimulated glucose disposal and subsequent oxidation, although the endogenous glucose production was increased. Recent studies showed treatment with the humanized IL-6 receptor-inhibiting monoclonal antibody (tocilizumab) helps to manage inflammatory disorders such as RA, however, an excessive weight gain, impaired metabolic homeostasis and hyperlipidemia is associated with the treatment (Febbraio et al. 2010). Animal studies supported this result, IL- $6^{-/-}$mice are protected from several diseases, but paradoxically they developed adult-onset obesity and glucose intolerance (Wallenius et al. 2002). On the other hand overexpressed human IL-6 in mice had increased insulin sensitivity and prevented the development of dietinduced obesity (Sadagurski et al. 2010). There is increasing evidence that IL-6 and TNF alpha act in a different manner on insulin sensitivity. TNF alpha impairs glucose disposal in skeletal muscle. Indeed, some data demonstrate that IL-6 can attenuate increases in TNF alpha (Tanaka et al. 2001). These findings collectively suggest a complex interplay among inflammatory mediators and metabolic processes. Furthermore, increased cardiovascular mortality and morbidity observed in RA can be explained by a different site of action of the systemic inflammatory mediators such myocardium or blood vessels.

In our study we observed comparable glucose metabolism in RA patients on low-dose glucocorticoids and patients without the treatment or healthy controls. Dessein et al. (2004) demonstrated high doses of pulsed glucocorticoids were independently associated with decreased insulin sensitivity after controlling for body mass index. In a different study, the authors did not find any difference in index if insulin resistance HOMA and QUICKI between patients with or without glucocorticoid treatment (Dessein and Joffe 2006). The effect of lowdose glucocorticoid treatment on glucose homeostasis depends also on the time of the last application. Moreover cumulative dose of glucocorticoids is strongly associated with index of beta cell function based on fasting plasma glucose and insulin concentrations (Dessein and Joffe 2006). Development of insulin resistance depends on dose of glucocorticoids as well as on a presence of other risk factors such is obesity, bad nutritional habit and physical inactivity. Low-dose glucocorticoid therapy ( $7.5 \mathrm{mg}$ of prednisolone) for 2 weeks in healthy subjects decreased ability of insulin to suppress endogenous glucose production and lipolysis, but did not affect peripheral glucose disposal. It is clear that high-dose of glucocorticoids has negative effect on many metabolic parameters (van Raalte et al. 2009, van Raalte et al. 2011a,b). Recent study of van Raalte et al. (2011a,b) indicated that the GLP-1 receptor agonist exenatide might prevent glucocorticoid-induced glucose intolerance and islet-cell dysfunction therefore incretin-based therapies represent a potential strategy to prevent steroid diabetes. Our results indicate that low-dose glucocorticoid treatment with duration of 2-9 years is relatively safe and did not lead to glucose metabolism impairment yet.

In conclusion, our results demonstrate that despite high inflammatory activity RA patients without other metabolic risk factors including obesity, higher age, hypertension or smoking did not differ in glucose metabolism to age, sex and BMI matched healthy subjects. Low-dose glucocorticoids treatment did not have a significant effect on glucose metabolism and insulin sensitivity in young women, however, a negative effect of the treatment with preexisting metabolic risk factors cannot be excluded.

\section{Conflict of Interest}

There is no conflict of interest. 


\section{Acknowledgements}

Authors appreciate Mrs. Emilia Andelova for her skillful technical assistance. This work was supported by the grants VEGA 2/6157/26, VEGA 2/0187/09, MZ2005/20NURCH-04, CENDO, NFM/EEA SK0095 and N00024 RASGENAS.

\section{References}

CEDERHOLM J, WIBELL L: Insulin release and peripheral sensitivity at the oral glucose tolerance test. Diabetes Res Clin Pract 10: 167-175, 1990.

CHUNG CP, OESER A, SOLUS JF, GEBRETSADIK T, SHINTANI A, AVALOS I, SOKKA T, RAGGI P, PINCUS T, STEIN CM: Inflammation-associated insulin resistance: differential effects in rheumatoid arthritis and systemic lupus erythematosus define potential mechanisms. Arthritis Rheum 58: 2105-2112, 2008.

DA SILVA JA, JACOBS JW, KIRWAN JR, BOERS M, SAAG KG, INES LB, DE KONING EJ, BUTTGEREIT F, CUTOLO M, CAPELL H, RAU R, BIJLSMA JW: Safety of low dose glucocorticoid treatment in rheumatoid arthritis: published evidence and prospective trial data. Ann Rheum Dis 65: 285-293, 2006.

DEL RINCON ID, WILLIAMS K, STERN MP, FREEMAN GL, ESCALANTE A: High incidence of cardiovascular events in a rheumatoid arthritis cohort not explained by traditional cardiac risk factors. Arthritis Rheum 44: 2737-2745, 2001.

DESSEIN PH, JOFFE BI: Insulin resistance and impaired beta cell function in rheumatoid arthritis. Arthritis Rheum 54: 2765-2775, 2006.

DESSEIN PH, JOFFE BI, STANWIX AE, CHRISTIAN BF, VELLER M: Glucocorticoids and insulin sensitivity in rheumatoid arthritis. J Rheumatol 31: 867-874, 2004.

DESSEIN PH, TOBIAS M, VELLER MG: Metabolic syndrome and subclinical atherosclerosis in rheumatoid arthritis. $J$ Rheumatol 33: 2425-2432, 2006.

FEBBRAIO MA, ROSE-JOHN S, PEDERSEN BK: Is interleukin-6 receptor blockade the Holy Grail for inflammatory diseases? Clin Pharmacol Ther 87: 396-398, 2010.

FERNANDEZ-REAL JM, RICART W: Insulin resistance and chronic cardiovascular inflammatory syndrome. Endocr Rev 24: 278-301, 2003.

GONZALEZ A, MARADIT KREMERS H, CROWSON CS, NICOLA PJ, DAVIS JM, THERNEAU TM, ROGER VL, GABRIEL SE: The widening mortality gap between rheumatoid arthritis patients and the general population. Arthritis Rheum 56: 3583-3587, 2007.

HOTAMISLIGIL GS, SHARGILL NS, SPIEGELMAN BM: Adipose expression of tumor necrosis factor-alpha: direct role in obesity-linked insulin resistance. Science 259: 87-91, 1993.

LA MONTAGNA G, CACCIAPUOTI F, BUONO R, MANZELLA D, MENNILLO GA, ARCIELLO A, VALENTINI G, PAOLISSO G: Insulin resistance is an independent risk factor for atherosclerosis in rheumatoid arthritis. Diab Vasc Dis Res 4: 130-135, 2007.

LIBBY P: Role of inflammation in atherosclerosis associated with rheumatoid arthritis. Am J Med 121: S21-S31, 2008.

MARADIT-KREMERS H, NICOLA PJ, CROWSON CS, BALLMAN KV, GABRIEL SE: Cardiovascular death in rheumatoid arthritis: a population-based study. Arthritis Rheum 52: 722-732, 2005.

MARI A, TURA A, PACINI G, KAUTZKY-WILLER A, FERRANNINI E: Relationships between insulin secretion after intravenous and oral glucose administration in subjects with glucose tolerance ranging from normal to overt diabetes. Diabet Med 25: 671-677, 2008.

MATSUDA M, DEFRONZO RA: Insulin sensitivity indices obtained from oral glucose tolerance testing: comparison with the euglycemic insulin clamp. Diabetes Care 22: 1462-1470, 1999.

MATTHEWS DR, HOSKER JP, RUDENSKI AS, NAYLOR BA, TREACHER DF, TURNER RC: Homeostasis model assessment: insulin resistance and beta-cell function from fasting plasma glucose and insulin concentrations in man. Diabetologia 28: 412-419, 1985.

MCKELLAR GE, MCCAREY DW, SATTAR N, MCINNES IB: Role for TNF in atherosclerosis? Lessons from autoimmune disease. Nat Rev Cardiol 6: 410-417, 2009. 
MEUNE C, TOUZE E, TRINQUART L, ALLANORE Y: High risk of clinical cardiovascular events in rheumatoid arthritis: Levels of associations of myocardial infarction and stroke through a systematic review and metaanalysis. Arch Cardiovasc Dis 103: 253-261, 2010.

NARANJO A, SOKKA T, DESCALZO MA, CALVO-ALEN J, HORSLEV-PETERSEN K, LUUKKAINEN RK, COMBE B, BURMESTER GR, DEVLIN J, FERRACCIOLI G, MORELLI A, HOEKSTRA M, MAJDAN M, SADKIEWICZ S, BELMONTE M, HOLMQVIST AC, CHOY E, TUNC R, DIMIC A, BERGMAN M, TOLOZA S, PINCUS T; QUEST-RA GROUP: Cardiovascular disease in patients with rheumatoid arthritis: results from the QUEST-RA study. Arthritis Res Ther 10: R30, 2008.

PAMUK ON, UNLU E, CAKIR N: Role of insulin resistance in increased frequency of atherosclerosis detected by carotid ultrasonography in rheumatoid arthritis. J Rheumatol 33: 2447-2452, 2006.

PAOLISSO G, VALENTINI G, GIUGLIANO D, MARRAZZO G, TIRRI R, GALLO M, TIRRI G, VARRICCHIO M, D'ONOFRIO F: Evidence for peripheral impaired glucose handling in patients with connective tissue diseases. Metabolism 40: 902-907, 1991.

PEDERSEN BK, FEBBRAIO M: Muscle-derived interleukin-6 - a possible link between skeletal muscle, adipose tissue, liver, and brain. Brain Behav Immun 19: 371-376, 2005.

PEMBERTON PW, AHMAD Y, BODILL H, LOKKO D, HIDER SL, YATES AP, WALKER MG, LAING I, BRUCE IN: Biomarkers of oxidant stress, insulin sensitivity and endothelial activation in rheumatoid arthritis: a cross-sectional study of their association with accelerated atherosclerosis. BMC Res Notes 2: 83, 2009.

ROCHA VZ, LIBBY P: Obesity, inflammation, and atherosclerosis. Nat Rev Cardiol 6: 399-409, 2009.

ROSENVINGE A, KROGH-MADSEN R, BASLUND B, PEDERSEN BK: Insulin resistance in patients with rheumatoid arthritis: effect of anti-TNFalpha therapy. Scand J Rheumatol 36: 91-96, 2007.

SADAGURSKI M, NORQUAY L, FARHANG J, D'AQUINO K, COPPS K, WHITE MF: Human IL6 enhances leptin action in mice. Diabetologia 53: 525-535, 2010.

SATTAR N, GAW A, SCHERBAKOVA O, FORD I, O'REILLY DS, HAFFNER SM, ISLES C, MACFARLANE PW, PACKARD CJ, COBBE SM, SHEPHERD J: Metabolic syndrome with and without C-reactive protein as a predictor of coronary heart disease and diabetes in the West of Scotland Coronary Prevention Study. Circulation 108: 414-419, 2003a.

SATTAR N, MCCAREY DW, CAPELL H, MCINNES IB: Explaining how "high-grade" systemic inflammation accelerates vascular risk in rheumatoid arthritis. Circulation 108: 2957-2963, 2003b.

SHOELSON E, LEE J, GOLDFINE AB: Inflammation and insulin resistance. J Clin Invest 116: 1793-1801, 2006.

STOUTHARD JM, ROMIJN JA, VAN DER POLL T, ENDERT E, KLEIN S, BAKKER PJ, VEENHOF CH, SAUERWEIN HP: Endocrinologic and metabolic effects of interleukin-6 in humans. Am J Physiol 268: E813E819, 1995.

SVENSON KL, POLLARE T, LITHELL H, HALLGREN R: Impaired glucose handling in active rheumatoid arthritis: relationship to peripheral insulin resistance. Metabolism 37: 125-130, 1988.

TANAKA T, KANDA T, MCMANUS BM, KANAI H, AKIYAMA H, SEKIGUCHI K, YOKOYAMA T, KURABAYASHI M: Overexpression of interleukin-6 aggravates viral myocarditis: impaired increase in tumor necrosis factor-alpha. J Mol Cell Cardiol 33: 1627-1635, 2001.

TOMS TE, PANOULAS VF, DOUGLAS KM, GRIFFITHS HR, KITAS GD: Lack of association between glucocorticoid use and presence of the metabolic syndrome in patients with rheumatoid arthritis: a crosssectional study. Arthritis Res Ther 10: R145, 2008.

VAN RAALTE DH, OUWENS DM, DIAMANT M: Novel insights into glucocorticoid-mediated diabetogenic effects: towards expansion of therapeutic options? Eur J Clin Invest 39: 81-93, 2009.

VAN RAALTE DH, BRANDS M, VAN DER ZIJL NJ, MUSKIET MH, POUWELS PJ, ACKERMANS MT, SAUERWEIN HP, SERLIE MJ, DIAMANT M: Low-dose glucocorticoid treatment affects multiple aspects of intermediary metabolism in healthy humans: a randomised controlled trial. Diabetologia 54: 2103-2112, 2011a.

VAN RAALTE DH, VAN GENUGTEN RE, LINSSEN MM, OUWENS DM, DIAMANT M: Glucagon-like peptide-1 receptor agonist treatment prevents glucocorticoid-induced glucose intolerance and islet-cell dysfunction in humans. Diabetes Care 34: 412-417, 2011 b. 
WALLACE TM, LEVY JC, MATTHEWS DR: Use and abuse of HOMA modeling. Diabetes Care 27: 1487-1495, 2004.

WALlENIUS V, WALLENIUS K, AHREN B, RUDLING M, CARLSTEN H, DICKSON SL, OHLSSON C, JANSSON JO: Interleukin-6-deficient mice develop mature-onset obesity. Nat Med 8: 75-79, 2002.

WANG L, FENG G: Rheumatoid arthritis increases the risk of coronary heart disease via vascular endothelial injuries. Med Hypotheses 63: 442-445, 2004.

YUDKIN JS, KUMARI M, HUMPHRIES SE, MOHAMED-ALI V: Inflammation, obesity, stress and coronary heart disease: is interleukin-6 the link? Atherosclerosis 148: 209-214, 2000. 